\title{
CAPACITAÇÃO DE RECURSOS HUMANOS: ALGUMAS EXPERIÊNCIAS
}

\section{FORMATION DE PERSONNEL QUALIFIÉ: QUELQUES EXPERIENCES}

Denize Cristina de Oliveira (org.) ${ }^{1}$

OLIVEIRA, D.C. (org.) et al. Capacitação de Recursos Humanos: Algumas Experiências. Rev. Bras. Cresc. Des. Hum. lll (1 ): São Paulo, 1993.

\section{RESUMO}

O presente trabalho relata algumas iniciativas de organizações governamentais e não governamentais na capacitação de agentes institucionais e comunitárias.

As experiências apresentadas aqui têm como premissa básica a busca de novos referênciais teóricos e metodológicos que possibilitem a construção conjunta de conhecimentos. Tais experiências, que se multiplicam pelo pais, abordam as áreas de saúde, educação, participação e desenvolvimento da cidadania.

A socialização de experiências e sua discussão é o objetivo de todas as instituições que aqui apresentam suas práticas.

\section{RÉSUMÉ}

L'arlicle décrit quelques initiatives d'organisations non gouvernementales dans la formation d'agents institutionnels et communautaires.

Les expériences présentées constituent une base de recherche de nouvelles références théoriques et méthodologiques qui permettent l'élargissement des connaissances. Des expériences simmilaires, de plus en plus nombreuses, se déroulent dans les domaines de la santé, de l'éducation, de la participation et du développement de la citoyenneté.

La socialisation des expériences et leur discussions est le büt recherché par toutes les institutions qui présentent ici leur pratique.

Tcxto elaborado a partir de experiências relatadas no I Semináro Brasil-França de "Formação Participativa de Recursos Humanos para a Criança de 0 - 6 anos” - Brasília, 30/08 a 04/09/92.

1 Pesquisadora e Diretora de Publicações do CDIH/FSP/USP. End.: Av. Dr. Amaldo, 715 - Subsolo - Cerqueira Cesar - São Paulo - Brasil - CEP 01255-090. 


\section{INTRODUÇÃO}

Parece não haver mais dúvida de que, modernamente, os processos de capacitação em geral evolu ram no sentido de se configurarem como relações pedagógicas do tipo dialógico, onde, no sentido que PAULO FREIRE coloca em "Comunicação e Extensão" (1) sujeitos diferentes, porém não assimétricos, interagem diante de um objeto comum, no caso a temática particular de cada processo de capacitação.

Processos de capacitação envolvendo metodologia participativa devem ter, portanto, esta concepção pedagógica como um de seus substratos teóricos. Mas é preciso entender com clareza o sentido de "participação" no contexto dos processos de capacitação.

Se, por um lado, esta "participação" está a indicar a superação de um modelo pedagógico autorit rio e assimétrico em que se tem, num polo, um sujeito - o capacitador- que "sabe" e, num outro polo, um objeto - o capacitado -, no qual é depositado o saber capacitador, isto não significa que desaparecem as figuras do capacitador e do capacitado.

No entanto, se estas diferentes perspectivas frente ao ato pedagógico permanecem, estes personagens se unificam diante de umprocesso comum - acapacitação - no qual ambos os atores se engajam ativamente.

Com efeito, a diferença espec fica entre o treinamento convencional e os processos de capacitação envolvendo metodologia participativa é que nestes últimos, justamente, há um engajamento, um vlnculo afetivo ativo do capacitador e do capacitado com o processo de capacitação.

Este engajamento e a defesa de posições que ele implica têm como coúsequência que nos processos de capacitação participativa a perspectiva mais teórica do capacitador é afetada pela perspectiva mais prática do capacitado e, viceversa, a perspectiva mais prática do capacitado é afetada pela mais teórica do capacitador.

Podemos igualmente colocar, numa perspectiva também sugerida pela pedagogia freireana ou pós-freireana, que estes dois atores, no contexto em qucstão, entram em relação dialética de conflito, da qual deve resultar uma sintese que modifica a situação inicial de ambos: o capacitador com sua teoria fecundada e, não poucas vezes, contestada pela prática e o capacitado, com sua prática afetada e modificada pela reflexão.

Enfim, a capacitação pedagógica envolvendo metodologia participativa é uma conquista que veio para ficar, constituindo sujeitos pedagógicos com perspectivas distintas porém envolvidos numa relação simétrica, que questiona o autoritarismo não apenas eticamente, mas também em beneficio da eficácia

Foi a partir da perspectiva acima que se desenvolveram os trabalhos do I Seminário BrasilFrança sobre "Formação Participativa de Recursos Humanos para a Criança de 0 -6 anos". Durante os trabalhos foram apresentadas diversas experiências que perseguem esse referencial teórico-metodológico, que passamos a apresentar.

\section{CNBB - PASTORAL DA CRIANÇA ${ }^{2}$}

A Pastoral da Criança da Conferência Nacional de Bispos no Brasil-CNBB é uma das pastorais da linha social da Igreja e foi iniciada em 1983 em Florestópolis no Paraná. A abrangência da Pastoral da Criança é a seguinte: ela está presente em 26 unidades federadas do Brasil, são 1660 municípios brasileiros, uma presença significativa em termos de território nacional, com uma distribuição bem equilibrada e uma concentração maior nos estados do Norte e Nordeste, onde existe uma carência maior de assistência à criança. São 13.984 comunidades cadastradas com 47.363 lideres comunitárias que acompanham 1.054.605 famílias, 77.203 gestantes e 1.535.220 crianças (dados do $3^{\circ}$ trimestre de 1992).

É nesse universo que a Pastoral está fazendo o trabalho de capacitação de agentes comunitárias, um universo significativo segundo a avaliação do UNICEF.

Quando a Pastoral da Criança foi implantada, seu objetivo principal era a redução da mortalidade infantil, isto se deu sob o signo da luta desesperada pela sobrevivência infantil.

Ao longo de seu trabalho passou a sofrer uma série de modificações. Hoje em dia seu objetivo não é só isso, apesar de ser o pano de fundo do trabalho. Colaborar para que as crianças tenham vida em abundância signifi ca que não basta sobreviver, é preciso que haja qualidade de vida não s6 para as crianças, mas para os pais também

A Pastoral tem como elemento central do seu foco de ação a criança e a mulher. Sua atividade de formação não se restringe à capacitação

2 Everardo de Carvalho, Assistente Técnico em Comunicação Social da Coordenação Nacional da Pastoral da Criança.

End.: Rua Pasteur, 279 - Curitiba/PR - Brasil - CEP 80250-080 e Márcia Mendes Mamede, Assessora em Educação Essencial da Coordenação Nacional da Pastoral da Criança.

End.: SGAN - L2 Norte - Quadra 601- conj. B - Brasília/DF - Brasil - CEP 70830-010. 
de lideres, na realidade a lidar comunitária é uma animadora do trabalho de emancipação e conscicntização da mulher.

A estrutura organizacional da Pastoral é a seguinte: uma coordenação nacional para gerenciar todo o processo, que tem como base fundamental 6 técnicos de nível superior, as coordenações estaduais, as coordenações diocesanas, as coordenações paroquiais e comunitárias. Todo o processo de trabalho é feito descentralizadamente, ou seja, os técnicos não participam de nenhuma atividade diretamente, eles formam os formadores que formam outros formadores, e ao fina' os animadores do processo. Na realidade é um trabalho que ocorre em forma disseminada

A opção pedagógica libertadora da Pastoral é baseada na co-construção do conhecimento. E um processo de educação continuada, que tem por base uma estrutura de encontros periódicos, onde todos os conteúdos, as práticas, as dificuldades são reelaborados. O material pedagógico utilizado está sempre sofrendo transformações de acordo com essas múltiplas interações.

Gostaríamos de destacar que o objetivo da Pastoral é trabalhar com a familia, acreditando que o trabalho de educação e de saúde só funciona se comecar no nível familiar, não adiantando deslocar isso só para o Centro Comunitário, Posto de Saúde, etc.

A Pastoral da Criança não executa só ações de saúde, ela trabalha basicamente em educação, as ações básicas desenvolvidas pela Pastoral são: assistência à gestante, aleitamento matemo, acompanhamento do crescimento, educação essencial desde o ventre materno, reidratação oral, incentivo e controle da imunização, alternativas alimentares.

Vale ressaltar que a Pastoral da Criança não faz trabalho paralelo às instituições governamentais. Por exemplo, na assistência à gestante ela não faz pré-natal: seus líderes comunitárias vão a uma casa onde tem uma mulher gestante conversar com ela e falar da importancia de fazer o pré-natal e explicar a ela quais os conteúdos de um pré-natal decente, ou seja, que ela tem que ser acompanhada no peso, que ela tem que fazer exame de sangue e de urina, um médico tem que tirar a pressão, tem que procurar ver como é que está o nenê, exigir boas condições de parto. Após o parto a líder fica ao lado dela, conversando, apoiando, orientando o aleitamento materno. A Pastoral ajuda a informar e organizar as famílias e comunidades dentro de uma mística cristã que junta fé e vida

O acompanhamento do desenvolvimento da criança é feito através do peso mensal, da educação essencial, do incentivo à imunização, da reidratação oral, das alternativas alimentares e do controle das infecções respiratórias.

A Pastoral superou a questão do micro, da questão específica da saúde da criança e hoje em dia tem trabalhado com o aspecto mais macro, hoje trabalha com o processo de formação da consciência política da cidadania

Está atualmente junto com o Conselho Nacional de Secretários Municipais de Saúde, com a chamada "Carta Compromisso pela Criança”, que traz a proposta de municipalizar o Pacto pela Infância.

Uma atividade que representa um salto qualitativo da Pastoral da Criança é a "Educação Essencial” que passa a investir não s6 na sobrevivencia, mas sim na questão da própria qualidade de vida

\section{Educação Essencial}

Para a Pastoral da Criança, a educação é um processo histórico, permanente e coletivo, devendo permitir a apropriação e a produção de conhecimentos. E não relega o conteúdo político ideológico da ação educativa, mesmo que seja no ambito restrito da família. Quando fala de Educação Essencial quer defender o direito de toda criança de ser educada na família e na escola. Criança e adulto tomam consciência de seu desenvolvimento e de sua educação, que são construídos no meio sócio-cultural onde vivem, valorizando-se e ampliando-se seus conhecimentos e experiências.

O reconhecimento de que todo indivíduo tem potencialidades a serem desenvolvidas e valores que merecem respeito, supera a visão de intervenção assistencialista, compensatória e paternalista. Esse trabalho de educação essencial se traduz numa ação básica daPastoral da Criança, que of erece um material didático especifico contido no "Guia do Lider" e num "Manual de Treinamento” para as coordenações diocesanas e paroquiais. O “Guia do Lider” traz conteúdo dirigido à lideres comunitários e às famílias.

O programa de Educação Essencial da Pastoral da Criança aborda as condições indispensáveis, que não devem faltar à criança nenhuma, seja ela de baixa renda ou não. Nessa perspectiva, equipes diocesanas e paroquiais são preparadas e dão trehiamento a lideres comunitárias em áreas urbanas e rurais.

A experiência de implantação da educação essencial em comunidades vem sendo efetivada desde janeiro de 1991.

Após um acompanhamento sistemático e próximo das primeiras experiências em 2 comunidades no Paraná, foram feitos ajustes na metodologia e no material educativo. Começou-se en- 
tão a capacitar equipes de treinamento dos estados do Nordeste em Setembro de 1991. Primeiro foram preparadas as equipes diocesanas, das capitais dos estados que por sua vez prepararam as equipes paroquiais. Depois, estas passaram suas experiências às populações, criando-se, assim, comunidades de experiência ou "experiências piloto”, numa ação educativa que se amplia gradativamente.

Neste ano o projcto foi ampliado para o Sul e parte do Centro-Oeste onde os Estados já estão estabelecendo suas próprias equipes e dando treinamento nas dioceses.

Para 1993, terão continuidade os treinamentos para o Sudeste e Norte e o restante do Centro-Oeste, e pretende-se agilizar o acompanhamento, que é o "calcanhar de Aquiles" de qualquer programa educacional. Propor-se-á encontros regionais para discutir, inclusive, o conteúdo e a metodologia de Educação Essencial, além de intensivas avaliações da prática. Ainda no final de 1992, realizar-se-ão dois encontros com equipes do Nordeste e do Sul para avaliar os resultados, fazer reformulações e tomar decisões sobre a atuação no próximo ano.

\section{$\mathrm{OMEP}^{3}$}

A Organização Mundial para a Educação Pré-Escolar (OMEP) é uma organização de educação pré-escolar, de caráter filantrópico que desenvolve uma proposta de formação de recursos humanos. Pretende superar a dicotomia entre teoria e prática, substituir a formação calcada na simples transmissão de conhecimento pela análise crítica do saber.

A proposta da OMEP é de que os cursos para capacitação de professores sejam efetuados com uma carga horária mínima de 80 horas. No Mato Grosso do Sul já estamos capacitando professores com uma carga horária de 120 ou até 240 horas, conjugando teoria e prática.

Nessa experiência, conseguimos fazer o professor ler e produzir seus $\operatorname{propr}^{\wedge}$ los textos a partir da leitura realizada. Pesquisas efetuadas no Estado indicam que esses professores não têm lido um livro sequer por ano. Embora com as dificuldades encontradas não só na aquisição de livros, como também na leitura e compreensão do que leram, os resultados têmnos incentivado a continuar a investir nesta proposta de trabalho.
Em Coxim realizamos um curso de capacitação em 120 horas desenvolvido em forma de módulos teóricos, oficinas pedagógicas, consultas bibliográficas, resenha e produção oral; ao final desse processo os professores de lá estavam lendo Constance Kamii,” A criança e o número" e já mostravam preocupação na aquisição de novos livros.

Nesse processo o primeiro passo foi fazêlos ler textos básicos, redigir um resumo e expôlos oralmente. Foi grande a dificuldade que tiveram, mas a repetição dessas tarefas deu-lhes mais confiança

Essa é a rcalidade do professor, não somente em nossa região,mas em toda a vastidão do interior nordestino e amazonense.

Neste ano, estamos levando esta proposta, garantindo a autonomia e a elaboração própria do professor às cidades de Campo Grande, Coxim, lardim, Três Lagoas, Corumbá, Paranaíba e Dourados, ampliando a interiorização de nossos objetivos. Nessas cidades os professores-alunos realizaram pesquisas bibliográficas, apesar da dificuldade em decodificar e interpretar 0 texto.

Eles tomaram consciência de que o livro é o mais valioso instrumento de trabalho na sua profissão.

Quanto às dificuldades financeiras para a compra de livros, foi sugerido que fizessem uma poupança mensal. Assim sendo, pode-se comprar 12 livros por ano, ou então seis, quatro ou pelo menos um. As Bibliotecas Municipais possuem um grande número de livros em suas estantes, mas não são utilizados, apenas servem como decoração, como é o caso das enciclopédias e colcções encadernadas. Por isso, estamos sugerindo às Prefeituras que adquiram livros que venham ampliar, aprofundar e complementar conhecimentos adquiridos.

Outra proposta que vale a pena destacar refere-se à mudança no curriculo dos cursos de formação de professores, tanto universitários como os de $2^{\circ}$ grau - Magistério, e pensando nisso a OMEP/BR/MS, com o apoio do Conselho Estadual de Educação conveniou-se a uma Faculdade de Educação para implantar um projeto relativo ao curso de "Estudos Adicionais-Habilitação especifica de professores para classes de pré-escolar", com o objetivo de propiciar condições de qualificação profissional e aprimoramento técnico a educadores que aluam na área de educação infantil. Este curso terá duração de um ano

3 Marisa M. Serrano. Presidente da Federação Estadual da OMEP/MS/BR.

End.: Rua 26 de Agosto, 114 - apto. 1 - Campo Grande/MS - Brasil - CEP 79002-080. 
com a carga horaria de 990 horas. Vale ressaltar que o referido curso possui critérios de seleção onde, para frequentá-lo, o candidato deverá ter concluido o $2^{\circ}$ grau - Magistério e estar atuando em sala de educação infantil.

Com relação à estrutura desse curso, o mesmo será realizado através de módulos, grupos de supervisão, trabalho pessoal, consulta bibliográfica e oficina pedagógica. Tudo isso objetivando of erecer subsídios teórico-práticos que possam auxiliar o professor-aluno numa atuação mais adequada como agente mediador no processo de aprendizagem da criança.

Acreditamos que não é apenas aumentando a carga horária que nós vamos mudar o perfil de formação do nosso professor, nossa proposta baseia-se no principio da interdisciplinariedade, onde a grade curricular abrangerá diferentes áreas do conhecimento, incluindo as do Núcleo Comum, portanto, estamos conscientes de que não é sé aumentar o número de disciplinas, mas é a mudança na sua abordagem que poderá ser proffcua.

\section{VISÃO MUNDIAL ${ }^{4}$}

A Visdo Mundial é uma organização crista, não governamental, sem fins lucrativos que faz parte de uma parceria internacional e que apoia técnica e financeiramente projetos sociais junto às comunidades empobrecidas.

Nos últimos anos a Visão Mundial tem experimentado mudanças marcadas por uma melhor explicitação de sua MISSÃO com a consequente (re)definição do Marco Conceirual e Metodológico do Desenvolvimenro Transformador. Estas definições possibilitam clarear o por quê e o que fazemos, que em última instancia tem implicações para os recursos humanos (capacitação, estratégia, metodologia, etc...). A capacitação tem se constituido na chave para promover as mudanças, objetivando melhorar a qualidade dos recursos humanos, e por conseguinte dos programas para a faixa etária de 0 a 6 anos. Em razão dessas definições, a Visão Mundial fez uma opção institucional de transformarse em uma Organiza^Fão Esrrarégica: flexivel, participativa, dina^tnica, decisões mais próximas de quem executa, etc..., buscando a flexibilidade, a criatividade, a participação, etc... Nessa medida a capacitação busca dois objetivos:

a) promover as mudanças culturais na Organização de maneira que a cultura burocrática, centralizadora,transforme-se em uma cultura de organização estratégica através de-um Programa de Educa^Fdo Con1ínua;

b) melhorar a qualidade dos recursos humanos (internos e externos) e por conseguinte dos programas educativos.

Neste breve histórico é importante destacar a peculiaridade da parceria da Visão Mundial com as comunidades. O acompanhamento envolve assessoramento direto e frequente no sentido de ajudar nos processos de análise da situação, avaliação de programas, discussão dos problemas, planejamento, organização comunitária, etc, e não apenas o financiamento.

Algumas premissas desta capacitação são: pessoas como agentes do processo demudança; enfoque centrado na educação e não no adestamento; enfoque na aprendizagem coletiva; enfoque na cultura da qualidade.

A cultura da qualidade busca trabalhar os seguintes aspectos: de processo; da mistica transcendental à espiritualidade; de pessoa na sua integralidade; material.

A proposta desenvolvida em todo CentroOeste nas localidades onde a Visão Mundial alua surgiu como resultado das seguintes inquietações:

a) atendimento inadequado às crianças de 0 a 6 anos;

b) formação precária das pessoas que prestavam serviços - inabilidade no trato com a criança, inadequação metodo-lógica e pedagógica;

c) ineficácia dos serviços de atendimento, etc...

A estratégia operativo no processo de formação constou dos seguintes segmentos:

1)Assessoria Externa - possibilitar o aprofundamento das questões teóricas a partir da prática das pessoas que vivenciam o desenvolvimento dos programas.

Considera-se a realidade local, dificuldades, inquietações e necessidades num processo de aço-reflexão construído coletivamente. A assessoria pelo distanciamento traz elementos interessantes para consideração, análise e crítica.

Foi constituído um grupo que recebeu capacitação sistemática que tinha responsabilidade de multiplicar os conhecimentos junto a outros públicos (educadores dos projetos, lideranças comunitárias e pais).

2) Formação do Supervisor (Facilitador) No princípio, teve periodicidade mensal depois bimestral e no momento está sendo feita de acordo com as demandas. O supervisor assessora, fa-

4 Serguem Jessui Machado da Silva, Administrador de Empresas, Coordenador de Recursos Humanos da Visão Mundial. End.: Rua Iretama, nº 549 - apto. 101- Contagem/MG - Brasil - CEP 32341-110. 
cilita e capacita o desenvolvimento de processos comunitárias. Seu papel é chave no sentido de desenvolver permanentemente as pessoas.

Dentro dos vários elementos do conteúdo da capacitação, alguns aspectos devem ser considerados: correntes de educação; subsídios teóricos sobre desenvolvimento infantil; desenvolvimento x aprendizagem; o papel do educador; educação infantil, etc...

A partir da capacitação deste nível é que se vai estabelecendo os outros elos da corrente. A eficácia é garantida basicamente pela continuidade (multiplicação) nos outros níveis, compromisso (crença e paixão) pessoal com a proposta e acompanhamento sistemático do pessoal.

A formação não é vista como um aio isolado e não tem ênfase no evento, mas no processo que envolve todo um conjunto de ações que vão sendo construídas cotidiana e coletivamente.

3) Formação de Educadores - É o elo principal da corrente, uma vez que são as pessoas que fazem acontecer, e sua formação se dá em vários momentos, envolvendo: sensibilidade da proposta - nova visão da criança: criança como sujeito e não como objeto de ação; capacitação inicial para todos os novatos; reciclagem duas vezes por ano; avaliação trimestral da prática do trabalho.

4) Formação de Lideranças Comunitárias - A capacitação deste segmento envolve vários aspectos, mas a questão da criança de $\mathrm{O}$ a 6 anos merece especial atenção para que o programa alcance o resultado desejado. Busca-se fundamentalmente a participação genuína que requer envolvimento e apoio efetivo. A possibilidade de sucesso está diretamente relacionada com a participação e engajamento de todos (pais e lideranças).

5) Acompanhamento - Consiste em visitas frequentes para prever, avaliar e discutir as dificuldades. E observada a educadora na sala de aula, reuniões são feitas com a comunidade (pais e lideranças). As avaliações são realizadas trimestralmente com todas as educadoras. A visita é realizada com base num roteiro que elenca os aspectos preponderantes a serem observados para posterior discussão. Este acompanhamento sistemático tem possibilitado a efetivação do fazer que implica em resultados objetivos a partir da confirmação ou correção dos rumos.

Os principais problemas enfrentados são: cobrança por parte dos pais dos resultados imediatos como por exemplo: alfabetização das crianças; inadequação dos espaços físicos; falta de vontade política das lideranças em apoiar o programa por desconhecimento; etc.

Este trabalho está sendo sistematizado e avaliado no sentido de possibilitar subsídios e pistas para uma melhor eficácia no processo de capacitação. Até o momento os resultados têm sido animadores pela adesão, boa vontade e disposição em mudar as práticas, algumas já ultrapassadas.

\section{UNICEF/CEARA ${ }^{5}$}

O UNICEF (Fundo das Nações Unidas para a Infancia) não desenvolve projetos próprios, mas participa e apoia os programas de iniciativa dos Estados, Municipios e 6rgãos não governamentais. O Estado do Ceará conta com uma política social definida para a infancia e adolescência, que dá animo de lutar pela educação da criança. Esse Estado demonstra, assim, que leva a sério o espírito da Constituição de 1988 e do Estatuto da Criança e do Adolescente.

Para falar do programa de creches comunitárias é preciso voltar ao ano de 1987, quando existiam apenas oito creches institucionais para atender, em média, quatro mil crianças. Foi proposta uma reestruturação completa, um novo modelo, começando pelo melhor aproveitamento da equipe e das amplas intalações. Esse novo modelo foi construído com a participação de lideranças comunitárias e associações e partiu daproposta de formação de creches comunitárias. De 8 creches institucionais passou-se a 196 creches comunitárias. Atualmente, o objetivo é passar de 206 para 400 creches até o final desta gestão governamental.

O sucesso foi possível com a intensa participação da comunidade, que se constitui, por si só, num processo de aprendizagem.

No programa de capacitação e educação infantil, temos dois projetos: o de educadores infantis e de capacitação de creches comunitárias. Os dois projetos estão baseados numa proposta de educação libertadora, democrática e participativa, com grande respeito à identidade cultural e à história da criança. A opção metodológica baseia-se na capacitação processual, dinamica e continua, onde a avaliação permanente é um elemento fundamental.

A criança é vista como um cidadão capaz de construir seu próprio conhecimento; por isso, a creche não é um lugar de guarda de crianças,

5 Stela M. Naspolini: Participação de Tania Gurgel e Alia Pequeno Holanda Porto respectivamente: Consultora do UNICEFi Presidente da Fundação do Bem Estar do Menor (E;EBEM-CE); Assessora Chefe de Recursos Humanos. End.: SBS - Ed. Seguradoras - 13º andar - Brasília/DF - Brasil - CEP 70072 - Fone: (061) 2247145. 
mas um espaço educativo, um direito e não um benefício para o menor.

No projeto de creches comunitárias, os capacitadores vão aos municípios das sete regiões administrativas do Ceará, onde ministram cursos de 24 horas (três dias de oito horas diárias). Participam apenas o pessoal que trabalha em creches comunitárias: monitores, coordenadores, cozinheiras, presidentes de associações; os temas abordados são: gerenciamento, educação, saúde e nutrição.

Pelo projeto de educadores infantis, os capacitadores vão a cada município, onde desenvolvemprocessos de capacitação de profissionais de creche, juntamente com professores de pré-escola, supervisores e diretores. O curso é de 40 horas em 4 momentos diferentes distribuídos em quatro meses, quatro horas diárias. Os temas levam em conta a criança no espaço cultural de sua comunidade, a criança e o educador e a criança e o espaço educativo, numa linha reflexiva e social.

Uma preocupação constante presente nesses processos é a integração saúde-educação, reunindo professores, nutricionistas e cozinheiras para uma ação conjunta. Neste sentido, é decisiva a participação da equipe da Secretaria de Saúde do Ceará, basicamente o pessoal do Viva Criança. Porque saúde e educação caminham de mãos dadas: sem um, o outro não avança.

Os professores e orientadores infantis são capacitados para o desenvolvimento de ações educativas junto às crianças, em temas como: reidratação oral, imunização, crescimento e desenvolvimento e aleitamento materno. Esse trabalho objetiva que as próprias crianças sejam agentes de mudança junto às suas famílias.

\section{AMEPPE}

A AMEPPE - Associação Movimento de Educação Popular Paulo Englert, vinculada à Fundação Fé e Alegria do Basil, enquanto uma organização não governamental vem atuando na área da criança e adolescente, desenvolvendo ações tanto no nível micro quanto no nível macro-estrutural. No primeiro nível, vempriorizando: a) o fortalecimento das organizações populares; b) a melhoria da qualidade de serviços e qualificação de pessoal. Já no segundo nível, nossa atuação tem se voltado para: a) a garantia dos direitos sociais e a definição e implantação de políticas so- ciais; b) a documentação, pesquisa e publicações. A atuação da AMEPPE no seu aspecto amplo acontece nas seguintes frentes de trabalho:

- articulação de entidades e movimentos na Frente de Defesa dos Direitos da Criança e do Adolescente (FDDCA);

- participação nos Conselhos de direitos nas diversas instancias,Nacional, Estadual e Municipal.

\section{Um espaço educativo}

A FDDCA, como todo movimento social, se caracteriza por uma dinâmica onde a participação de pessoas, grupos e movimentos ora tem um fluxo maior, ora menor. De modo que, nos momentos de discussão e pressão para aprovação de propostas de lei na Camara e Assembléia, a participação foi presente e forte e noutros momentos foi (é) menor, caracterizando-se por um fluxo e refluxo na participação. Outra de suas características é a grande flexibilidade na atuação, determinando um processo de avaliação constante para a reorientação e redefinição de prioridades.

A Frente tem respondido basicamente a uma demanda posta pela realidade social, onde a questão da violação dos direitos de crianças e adolescentes cotidianamente nos desafia e para isso é necessário fazer a todo momento, uma releitura dos acontecimentos, redimensionandoos com agilidade para dar respostas urgentes. A Frente tem se reconstituido em uma escola de formação política para a cidadania, na medida em que propicia uma outra relação com os direitos básicos do cidadão.

De modo geral, acreditamos que o processo de participação no interior da FDDCA tem sido muito rico. A participação de pessoas tanto do movimento popular (lideranças comunitárias), quanto de assessores e técnicos num mesmo espaço de discussão política tem se constituído numrico momento de aprendizado de alguns aspectos fundamentais para o exercício de cidadania. São nesses espaços que têm acesso efetivamente ao significado do direito e a necessidade de organização para efetivação daquilo que foi conquistado na forma da lei.

A estruturação do processo educativo na FDDCA comporta momentos diferenciados tais como:

- reuniões semanais com discussões, encaminhamentos de questões do dia a dia

5 Alice Magda Gontijo, assessora pedagógica e representante da AMEPPE no Conselho Municipal dos Direitos da Giança e do Adolescente de Belo Honzonte. End.: Av. Amazonas, 641 - conj. 8 B/CID - Centro - Belo Honzonte/MG - Brasil - CEP 80180000 Fone: (031)201-5434. 
da cidade/estado relacionados à criançaladolescente;

- seminários e debates de temas de aprofundamento (questão do adolescente autor de ato infracional e encaminhamentos jurídicos, função do Conselho Tutelar, etc.)

- debates com autoridades do poder público (enfocando temas como orçamento do município e outros).

\section{Alguns referenciais metodológicos}

Quanto à questão metodológica, temos aluado dentro da FDDCA a partir de referênciais da proposta metodológica mais ampla da AMEPPE. No entanto, no que se refere ao trabalho desenvolvido junto à FDDCA existem algumas especificidades por causa das dinamicas próprias do movimento social, demandando uma maior participação dos grupos, e/ou urgência dos encaminhamentos a serem dados enquanto ariiculação política.

No desenvolvimento do processo de participação temos sempre a preocupação de ampliar e adequar o debate aos grupos populares.

A metodologia comporta, entre outros fatores, o respeito pelo momento de cada um e seu grau de apropriação do conhecimento acerca do jurídico, do legislativo e do político. Busca-se valorizar a fala e nela os "silêncios" daquele que apreende o conhecimento, mas ainda não se sente seguro para explicitar respostas bem elaboradas.

O processo educativo não comporta graduação das dificuldades, já que os “conteúdos” são tirados da realidade social que é complexa e diversa.

Dentro da questão metodológica temos buscado explicitar alguns princípios importantes:

a) o ponto de partida fundamental da metodologia que procuramos desenvolver é a percepção de que os educadores/parceiros com quem trabalhamos, são sujeitos histórico-sociais que contraem relações, que têm uma prática social, que produzem e são donos de um saber. Entendemos também que estes sujeitos com quem trabalhamos não se definem somente pelo trabalho e/ ou por seu pertencimento a uma classe, mas pelo conjunto dos "momentos" constitutivos do seu "ser no mundo", a saber pela sua dimensão histórico-social, política, psicológica, económica...

b) ao trabalhammos com os educadores na elaboração da proposta educativa para as creches, tínhamos e temos claro que estaríamos trabalhando, de maneira especial, com seus saberes, mas não só com eles e sim com o "todo" do conjunto, e de cada um deles. Nossa proposta foi, então, de procurar criar meios para que, juntos, pudéssemos refletir sobre a realidade e sobre o saber de cada um de nós e do conjunto, na perspectiva de construir um novo saber e transformar mais eficazmente a realidade. c) sendo nossa perspectiva a de que o saber popular, assim como o chamado saber sistematizado, tem sua própria lógica e é permeado por contradições - contradições estas que fazem parte da realidade mesmo e não apenas se referem ao saber - nossa intenção sempre foi a de ir procurando, na reflexão, apontar para estas contradições no sentido de ir construindo um novo saber mais coerente e logicamente organizado segundo os anseios dos trabalhadores. Entendemos que uma tal postura é fundamental se queremos "quebrar" as aparências do real passar do "abstraio" do saber e das relações cotidianas ao entendimento e sua concretude histórica.

d) acreditamos que, ao longo do trabalho, pouco adiantaria toda nossa reflexão se não procurássemos coletivamente, a organização de nosso "saber sabido" e refletida em outros "patamares" que não o senso-comum. Sem termos o "saber popular" apenas como "ponto de partida” e 'não considerando o "saber sistematizado" como 'ponto de chegada”, mas ambos como construção histórica que estão numa relação dialética constante, sempre que necessário é possível buscarmos organizar o saber que estava sendo construído a partir da prática e das reflexões coletivas.

e) defender que o "saber popular" é importante e que o "saber sistematizado" não é "ponto de chegada", pode tornar-se um simples palavrório se não se buscar compreender as raízes históricas dos conhecimentos produzidos pelos homens, nas diversas áreas do saber, principalmente daqueles referentes à infância c à aprendizagem, foi uma de nossas constantes preocupações.

f) tínhamos claro que, para efetivar tal proposta metodológica, seria preciso irmos além de diversas experiências que conhecíamos e, muitas vezes, da nossa própria, e procurar construir e trabalhar com novos procedimentos e materiais pcdagógicos.

Postulamos que a metodologia voltada para princípios participativos tem necessariamente de rever as noções de participação até hoje utilizadas pelas políticas clientelistas do Estado. Isto significa também repensá-las em novas bases, redefinindo a responsabilidade do Estado enquanto financiados das políticas sociais básicas, e ao mesmo tempo o papel da sociedade civil na cogestão c controle da coisa pública.

\section{BIBLIOGRAFIA}

01. FREIRE, P. Extensão Ou Comünicação? Editora Paz e Terral Rio de Janeiro, 1982. 